\title{
High malaria transmission in a forested malaria focus in French Guiana: How can exophagic Anopheles darlingi thwart vector control and prevention measures?
}

\author{
Samuel B Vezenegho ${ }^{1}$, Antoine Adde ${ }^{1}$, Vincent Pommier de Santi ${ }^{2,3}$, Jean Issaly ${ }^{1}$, Romuald Carinci ${ }^{1}$, \\ Pascal Gaborit', Isabelle Dusfour', Romain Girod', Sébastien Briolant ${ }^{1}{ }^{13,4,5 /+}$ \\ 1'Institut Pasteur de la Guyane, Unité d'Entomologie Médicale, Cayenne, Guyane, France \\ ${ }^{2}$ Centre d'Epidémiologie et de Santé Publique des Armées, Marseille, France ${ }^{3}$ Direction Interarmées du Service de Santé en Guyane, \\ Cayenne, Guyane, France ${ }^{4}$ Institut de Recherche Biomédicale des Armées, Département des Maladies Infectieuses, \\ Unité de Parasitologie et d'Entomologie, Brétigny sur Orge, France ${ }^{5}$ Aix Marseille Université, \\ Unité de Recherche sur les Maladies Infectieuses et Tropicales Emergentes, Marseille, France
}

\begin{abstract}
In French Guiana, malaria vector control and prevention relies on indoor residual spraying and distribution of long lasting insecticidal nets. These measures are based on solid epidemiological evidence but reveal a poor understanding of the vector. The current study investigated the behaviour of both vectors and humans in relation to the ongoing prevention strategies. In 2012 and 2013, Anopheles mosquitoes were sampled outdoors at different seasons and in various time slots. The collected mosquitoes were identified and screened for Plasmodium infection. Data on human behaviour and malaria episodes were obtained from an interview. A total of 3,135 Anopheles mosquitoes were collected, of which Anopheles darlingi was the predominant species (96.2\%). For the December 2012-February 2013 period, the Plasmodium vivax infection rate for An. darlingi was $7.8 \%$, and the entomological inoculation rate was 35.7 infective bites per person per three-month span. In spite of high bednet usage (95.7\%) in 2012 and 2013, 52.2\% and $37.0 \%$ of the participants, respectively, had at least one malaria episode. An. darlingi displayed heterogeneous biting behaviour that peaked between 20:30 and 22:30; however, 27.6\% of the inhabitants were not yet protected by bednets by 21:30. The use of additional individual and collective protective measures is required to limit exposure to infective mosquito bites and reduce vector densities.
\end{abstract}

Key words: Anopheles darling - Plasmodium vivax - biting behaviour - entomological inoculation rate - malaria - French Guiana

Malaria in French Guiana, an overseas territory of France located on the northeast coast of South America, remains of public health importance even though the number of reported clinical cases has dropped from 4,479 cases in 2005 to 445 cases in 2014 (Ardillon et al. 2015). Since 2005, Plasmodium vivax has been predominant; this species was responsible for $67 \%$ of the reported malaria cases in the territory in 2014, the other cases were mainly due to $P$. falciparum (Carme et al. 2009, Musset et al. 2014, Ardillon et al. 2015). Most of the officially reported cases occur in villages located along the main rivers that flow through the territory. Moreover, it is clear that illegal gold mining areas are obviously relevant uncontrolled locations for malaria transmission (Pommier de Santi et al. 2016a, b, c). The coastal region

doi: 10.1590/0074-02760160150

Financial support: ARS (Conventions No $12-49 / A R S$ du 11 juillet 2012 and No 13-83/ARS du 28 juin 2013), and by the French Army (grant LR607e). This work benefited from an Investissement d'Avenir grant managed by Agence Nationale de la Recherche (CEBA, ref. ANR-10-LABX-25-01). This study received a European commission REGPOT-CT-2011-285837-STRonGer grant within the FP7.

+Corresponding author: sbriolant@wanadoo.fr

Received 17 April 2016

Accepted 12 July 2016 of the territory is home to $75 \%$ of the population and is essentially characterised by imported malaria cases from the inland areas, although autochthonous transmission is occasionally observed (Carme et al. 2009, Musset et al. 2014, Ardillon et al. 2015).

A total of 24 anopheline species have been reported in French Guiana (Talaga et al. 2015). One of these is Anopheles (Nyssorhynchus) darlingi, known as the most common malaria vector in the Americas and, consequently, also in the Amazon Region (Sinka et al. 2010, Hiwat \& Bretas 2011, Laporta et al. 2015). This species has been incriminated as the principal malaria vector in French Guiana at different periods and places (Floch \& Abonnenc 1951, Floch 1955, Girod et al. 2008, Hiwat et al. 2009, Fouque et al. 2010, Girod et al. 2011). Furthermore, other species (An. nuneztovari sl, An. oswaldoi sl, An. intermedius, An. marajoara and An. ininii) that have been found naturally infected with Plasmodium sporozoites in the wild are considered as secondary vectors, although their role in human transmission is still to be unravelled (Dusfour et al. 2012, Pommier de Santi et al. 2016a, b).

Malaria vector control in French Guiana is achieved through the distribution of long-lasting insecticidal nets (LLINs) and indoor residual spraying (IRS). Deltamethrin is the insecticide used for both approaches (CIRE 2006, Mansotte et al. 2010). Whereas IRS targets malaria vectors that rest inside houses, LLINs prevent contact between humans and mosquitoes, which often bite indoors 
when people are sleeping. The deltamethrin used in both strategies is supposed to protect the community by killing the vectors and interrupting local malaria transmission.

The effectiveness of LLINs is reduced when mosquitoes change their biting behaviour from times when LLINs users are under their nets to when they are not using them. In the same way, the effectiveness of IRS is reduced when mosquitoes adopt exophagic and exophilic behaviours.

Indeed, An . darlingi exhibits heterogeneous biting behaviour across its range. Indoor biting by this species has been reported in Belize (Roberts et al. 2002), while a tendency to bite outdoors has been noted elsewhere, including Brazil (Gil et al. 2003), Suriname (Rozendaal 1989, Hiwat et al. 2011) and Peru (Moreno et al. 2015). In French Guiana, this species has been collected while biting humans outside houses in both the coastal region and in forested areas (Pajot et al. 1977, Girod et al. 2008, Dusfour et al. 2010, 2013, Vezenegho et al. 2014, 2015). These entomological observations should be considered in the light of human behaviour to define an efficient and sustainable malaria vector control strategy. In particular, special attention should be given to the outdoor activities of residents from soon after sunset until the later part of the evening when they retire into their houses. The same issues may arise at dawn.

Beyond Anopheles human biting rates, the longevity of the female population is a key parameter in estimating the risk of malaria transmission. This risk can be assessed by measuring the parity of females (Detinova 1962). Indeed, older females are more likely to transmit the parasite given the length of its sporogonic cycle. However, data on the longevity of $A n$. darlingi populations are very scarce in French Guiana where parity is generally low (Girod et al. 2008, Hiwat et al. 2009, Fouque et al. 2010).

The success of malaria vector control strategies is reflected by a decrease in malaria transmission. Several indices such as parasite rate, annual parasite index, spleen rate and entomological inoculation rate can be used to measure malaria transmission (Hay et al. 2000, Smith \& McKenzie 2004, Smith et al. 2007, 2009). The entomological inoculation rate (EIR) is considered the most direct of these indices and provides an insight into the impact of malaria control measures. Moreover, it helps to identify areas of increased risk. The strength of EIR lies in the fact that it quantifies the parasite-infected mosquitoes and their probability of transmitting parasites to humans.

With the goal of maintaining the recent gains that have reduced the number of malaria cases in the territory, an entomological study was conducted in Blondin, a village located along the Oyapock River separating French Guiana from Brazil. The objectives were (i) to assess the biting behaviour of Anopheles mosquitoes and their role in malaria transmission, and (ii) to characterise human behaviour and investigate malarial episodes in relation to the ongoing malaria vector control and prevention strategies.

\section{MATERIALS AND METHODS}

Study site - The study was conducted in Blondin, French Guiana, a forested village located along the Oyapock River, which forms a natural boundary with Brazil, upstream of the town of Saint-Georges de l'Oyapock. A health centre is available to the municipality, which is occupied by 3,855 inhabitants (Fig. 1). Blondin village

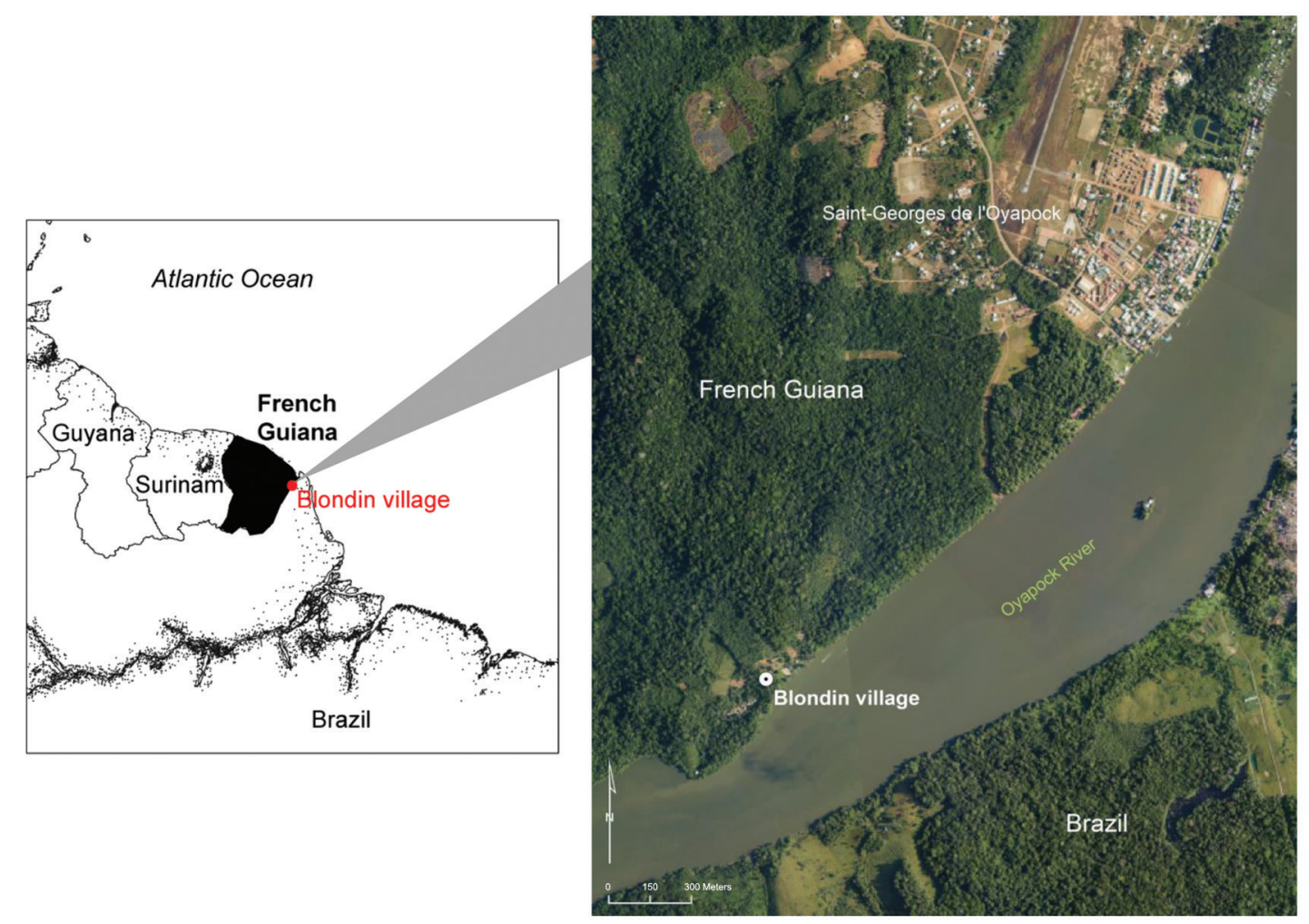

Fig. 1: localisation of the study site of Blondin village, Saint-Georges de l'Oyapock municipality, French Guiana. Orthophotograph acquired in 2006 by the French National Geographic Institute (BD-ORTHO ${ }^{\circledR}$ product). 
itself is home to approximately 60 inhabitants, primarily Amerindians and people of Brazilian origin. The village comprises 13 houses, which have wooden walls and corrugated aluminium roofs without ceilings. Inhabitants of the village engage in subsistent farming and fishing.

The climate of the study area is equatorial, and four seasons of unequal length can be distinguished: a long rainy season from April to June, a long dry season from July to December, a short rainy season from January to February and a short dry season in March. The short dry and wet seasons are yearly periods of low and high rainfall, respectively. The transition periods are the yearly intervals between these low and high rainfall periods. In French Guiana, the seasons are influenced by the migration of the inter-tropical convergence zone. In 2012 and 2013, the average annual rainfall was $3126.5 \mathrm{~mm}$ and $3131.1 \mathrm{~mm}$, respectively. During the study period, from December 2012 to February 2013 (session 1) and from September to November 2013 (session 2), average rainfall was $891.8 \mathrm{~mm}$ and $304.9 \mathrm{~mm}$, respectively. The average temperature is approximately $27^{\circ} \mathrm{C}$ with an average relative humidity of $80 \%$. In French Guiana, the average annual rainfall is approximately 3,000 millimetres.

Malaria in the village is mainly due to $P$. vivax. An increased incidence of cases is usually observed between October and December. Distribution of LLINs in Blondin village started in July 2012 with a coverage level of $100 \%$. Each year, IRS is implemented in September before the major peak in malaria cases.

In the municipality of Saint-Georges de l'Oyapock, 257 and 152 malaria cases were diagnosed in 2012 and 2013, respectively. P. vivax and P. falciparum were, respectively, responsible for $88.7 \%$ and $11.3 \%$ of malaria cases in 2012, and for $90.8 \%$ and $9.2 \%$ of malaria cases in 2013 .

Study design and mosquito collection - Mosquito collections were conducted in Blondin village from December 2012 to February 2013 (session 1) and from September 2013 to November 2013 (session 2). Mosquitoes were collected for four and three consecutive nights in the first week of each month for sessions 1 and 2, respectively. The collections were performed from 18:30 to 20:30, 20:30 to $22: 30$ and $05: 00$ to $07: 00$ by human landing catches (HLC). The collection sites were the same throughout the study. Mosquitoes were collected exclusively outdoors and close to houses. HLC were performed by two individuals, each acting as bait and collector following World Health Organization recommendations, whereby the lower legs are exposed and landing mosquitoes collected with a mouth aspirator (WHO 1975).

Field and laboratory processing - Anopheline species were identified morphologically using taxonomic keys specific to the region (Floch \& Abonnenc 1951, Forattini 1962, Faran \& Linthicum 1981). A subset of at most ten An. darlingi per day was dissected for determination of parity status by examining the conformation of tracheoles (Detinova 1962).

Genomic DNA extraction and Plasmodium species identification - DNA was extracted from the head and thorax of all female anopheline mosquitoes according to the protocol provided by the MagMAX ${ }^{\mathrm{TM}}-96$ DNA Multi-Sample kit (Applied Biosystems, USA). The resultant DNA in pools of ten was subjected to nested polymerase chain reaction (PCR) to detect Plasmodium DNA according to Snounou et al. (1993). Individually stocked DNA used to compose the pooled DNA was screened when a pool tested positive.

Survey interview - The interviews were conducted during the dry season in 2014 to avoid seasonal bias in the answers. The interview first explored socio-demographic characteristics such as age and gender, duration of residence in Blondin village and level of education. Participants were then asked whether they knew the role of mosquitoes in malaria transmission, the signs of malaria in adults and children and were questioned about the use of preventive measures (nets and repellents), their behaviour (the time they retire under bednets to sleep and the time they emerge from the bednets), and malaria history (episodes in 2012 and 2013, whether they had consulted a doctor and whether they took antimalarial drugs without instructions from a doctor). Interviews were performed in the presence of a translator for assistance in situations involving language barriers.

Data and statistical analysis - Human biting rates (HBR) were calculated as the total number of anopheline mosquitoes caught landing on humans, divided by the number of collectors, divided by the number of hours spent sampling. Plasmodium species infection rates were calculated as the number of specimens infected with the Plasmodium parasite divided by the total number of specimens tested. The entomological inoculation rate estimates the number of infective mosquito bites per person per unit of time. It is calculated as the product of the HBR and the infection rate (Birley \& Charlewood 1987).

All statistical analyses were performed with GraphPad Prism software (version 5.01). Quantitative variables were compared using Mann-Whitney tests. Percentages were compared by using Fisher's exact test. The comparison of Anopheles distributions between session 1 and 2 was performed by using Chi-square tests. The comparison of Anopheles distributions according to the collection time within a session was performed by using Chisquare tests for trend. Statistical results were considered significant when the p-value was below 0.05 .

Ethics - The collectors were local volunteer residents who were given training on HLC and informed of the associated risks of the collection method. They were supervised during the captures by the authors. Malaria prophylaxis was proposed and information on the medication was provided. Collectors who benefited from prophylaxis gave their free, express and informed consent. The interviews were anonymous and completed with the consent of all participants.

\section{RESULTS}

Anopheles species composition and human biting rates - A total of 3,135 Anopheles mosquitoes were collected (Table I). During session 1,274 specimens were collected and 95.6\% [CI95\% (92.5-97.7)] of the Anoph- 
TABLE I

Distribution and human biting rates (HBR) of Anopheles species collected in Blondin village, Saint-Georges de l'Oyapock municipality, French Guiana, using human landing catches from December 2012 to February 2013 (session 1) and September to November 2013 (session 2)

\begin{tabular}{|c|c|c|c|c|}
\hline Collection session & Species & Number $(\%)$ & Total hours of collection & $\begin{array}{c}\text { HBR } \\
\text { (number of bites/human/hour) }\end{array}$ \\
\hline \multirow[t]{6}{*}{1} & An. $s p$ & $12(4.4 \%)$ & 144 & 0.042 \\
\hline & An. braziliensis & $1(0.4 \%)$ & 144 & 0.003 \\
\hline & An. darlingi & $244(89.0 \%)$ & 144 & 0.847 \\
\hline & An. nuneztovari s.l. & $12(4.4 \%)$ & 144 & 0.042 \\
\hline & An. triannulatus s.l. & $5(1.8 \%)$ & 144 & 0.017 \\
\hline & Total & $274(100 \%)$ & 144 & 0.951 \\
\hline \multirow[t]{5}{*}{2} & An. $s p$ & $79(2.8 \%)$ & 108 & 0.366 \\
\hline & An. braziliensis & $2(0.1 \%)$ & 108 & 0.009 \\
\hline & An. darlingi & $2,773(96.9 \%)$ & 108 & 12.838 \\
\hline & An. nuneztovari s.l. & $7(0.2 \%)$ & 108 & 0.032 \\
\hline & Total & $2,861(100 \%)$ & 108 & 13.245 \\
\hline
\end{tabular}

TABLE II

Anopheles darlingi distribution and human biting rates (HBR) by collection time slots in Blondin village, Saint-Georges de l'Oyapock municipality, French Guiana, using human landing catches from December 2012 to February 2013 (session 1) and September to November 2013 (session 2)

\begin{tabular}{|c|c|c|c|c|}
\hline Collection session & Collection period & Number (\%) & Total hours of collection & $\begin{array}{c}\text { HBR } \\
\text { (number of bites/human/hour) }\end{array}$ \\
\hline \multirow[t]{4}{*}{1} & $18: 30-20: 30$ & $76(31.2 \%)$ & 46 & 0.264 \\
\hline & $20: 30-22: 30$ & $124(50.8 \%)$ & 46 & 0.430 \\
\hline & 05:00-07:00 & $44(18.0 \%)$ & 46 & 0.153 \\
\hline & Total & $244(100 \%)$ & 144 & 0.847 \\
\hline \multirow[t]{4}{*}{2} & $18: 30-20: 30$ & $934(33.7 \%)$ & 36 & 4.324 \\
\hline & $20: 30-22: 30$ & $892(32.2 \%)$ & 36 & 4.130 \\
\hline & 05:00-07:00 & $947(34.1 \%)$ & 36 & 4.384 \\
\hline & Total & $2,773(100 \%)$ & 108 & 12.838 \\
\hline
\end{tabular}

eles mosquitoes were identified as belonging to four species. An. darlingi was the predominant species $[89.0 \%$, CI95\% (84.7-92.5)] followed by An. nuneztovari sl [4.4\%, CI95\% (2.3-7.5)], An. triannulatus sl [1.8\%, CI95\% (0.64.2)] and An. braziliensis [0.4\%, CI95\% (0.0-2.0)]. During session 2, 2,861 Anopheles mosquitoes were collected and 97.2\% [CI95\% (96.6-97.8)] were identified as belonging to three species. An. darlingi was again the predominant species [96.9\%, CI95\% (96.2-97.5)], followed by An. nuneztovari sl [0.2\%, CI95\% (0.1-0.5)] and An. braziliensis [0.1\%, CI95\% (0.0-0.2)]. The difference in the distribution of Anopheles species between sessions 1 and 2 was statistically significant $(\mathrm{p}<0.0001$, Chi-square test). Regarding HBR, An. darlingi HBR was significantly higher than for other Anopheles species in both sessions ( $\mathrm{p}<0.0001$, Fisher's exact test). The HBR for An. darlingi was significantly higher during session 2 than during session 1 ( $\mathrm{p}<0.0001$, Fisher's exact test).

An. darlingi distribution and HBR by collection time - The distribution of An. darlingi by number and HBR according to the collection time and session are detailed in Table II. The distribution of An. darlingi density per collection time (Fig. 2) was significantly different between session 1 and $2(\mathrm{p}<0.001$, Chi-square test). There was no difference between the percentages of $\mathrm{An}$. darlingi collected regarding the time slots $(\mathrm{p}=0.71$, Chisquare test for trend) for session 1; however, there was a significant difference between the percentages of $A n$. darlingi regarding the collection time in session 2 ( $\mathrm{p}$ 


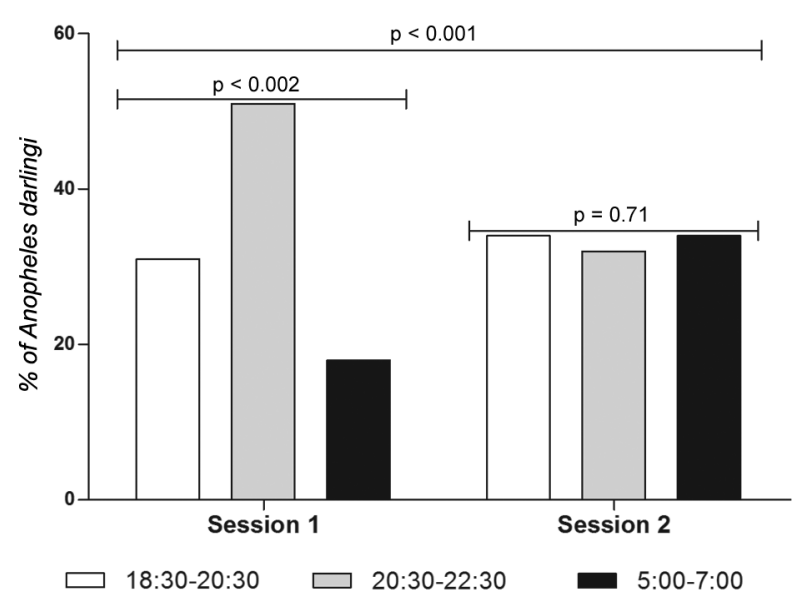

Fig. 2: percentage of Anopheles darlingi by collection time slot in Blondin village, Saint-Georges de l'Oyapock municipality, French Guiana, December 2012 to February 2013 (session 1) and September to November 2013 (session 2).

$=0.002$, Chi-square test for trend). The percentage of An. darlingi [50.8\%, CI95\% (44.4-57.3)] caught between 20:30 and 22:30 was significantly higher than those caught between $18: 30$ and 20:30 [31.2\%, CI95\% (25.437.4)] and between 05:00 and 7:00 [18.0\%, CI95\% (13.423.4)] respectively; $\mathrm{p}<0.0001$, Fisher's exact test.

An. darlingi infection rate, entomological inoculation rate and parity - None of the Anopheles mosquitoes collected during either session was infected with P. falciparum, and An. darlingi was the only species found infected with $P$. vivax during session 1, with an infection rate (IR) of $7.8 \%$ [n=19/244, CI95\% (4.8-11.9)]. There was no difference IR of An. darlingi with regard to the collection time ( $\mathrm{p}=0.81$, Chi-square test for trend). From $18: 30$ to $20: 30$, An. darlingi IR was $6.6 \%$, CI95\% (2.214.7); from $20: 30$ to $22: 30$, it was $8.9 \%$, CI95\% (4.5-15.3); and from $05: 00$ to $07: 00$, it was $6.8 \%$, CI95\% (1.4-18.7). A global EIR of 0.07 infective bites per person per hour was

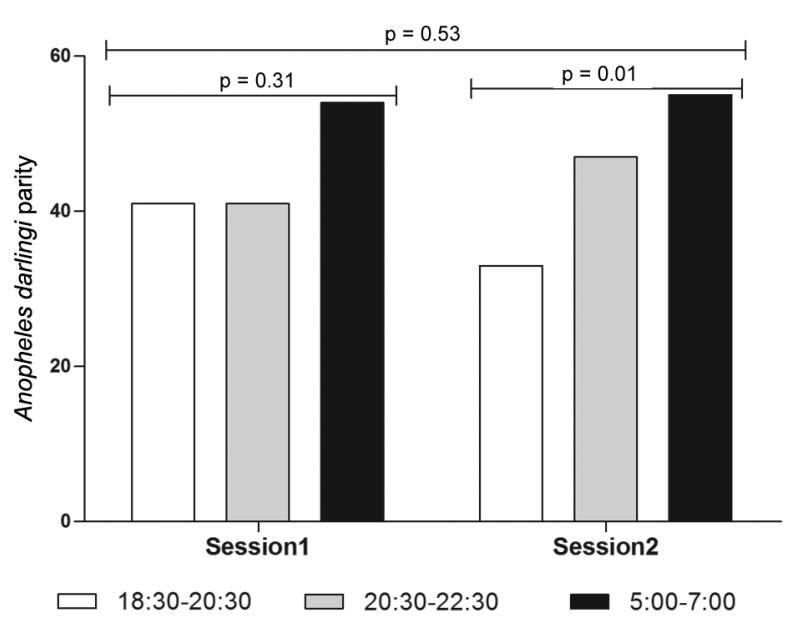

Fig. 3: dynamics in Anopheles darlingi parity in Blondin village, SaintGeorges de l'Oyapock municipality, French Guiana, December 2012 to February 2013 (session 1) and September to November 2013 (session 2).

obtained for An. darlingi during session 1. Considering that people were bitten during six hours per night (being under bednets the rest of the night), to estimate the level of malaria transmission during the high transmission risk period, a global three-months EIR was calculated, resulting in 35.7 infective bites per person per three months [CI95\% (25.0-49.4)]. However, none of the mosquitoes collected in session 2 was infected with $P$. vivax.

The parity per collection time obtained for a total of 315 An. darlingi females (106 and 209, respectively, for sessions 1 and 2) are presented in Fig. 3 and Table III.

There was no difference between the distributions of An. darlingi parity with regard to the collection time in session 1 and 2 ( $p=0.53$, Chi-square test), and during session 1, there was no difference in An. darlingi parity according to the time slot of collection ( $p=0.31$, Chi-square test for trend). However, during session 2, there was a significant difference in An. darlingi parity between the time slot of collection ( $p=0.01$, Chi-square test for trend). The

\section{TABLE III}

Anopheles darlingi parity by collection time slot in Blondin village, Saint-Georges de l'Oyapock municipality, French Guiana, using human landing catches from December 2012 to February 2013 (session 1) and September to November 2013 (session 2)

\begin{tabular}{ccccccc}
\hline Session & Collection period & Number & Parous & Non parous & Undetermined & Parity (CI95\%) \\
\hline 1 & $18: 30-20: 30$ & 76 & 20 & 29 & 0 & $40.8(27.0-55.8)$ \\
$20: 30-22: 30$ & 124 & 12 & 17 & 0 & $41.4(23.5-61.1)$ \\
$05: 00-07: 00$ & 44 & 15 & 13 & 0 & $53.6(33.9-72.5)$ \\
Total & 244 & 47 & 59 & 0 & $44.3(34.9-53.8)$ \\
\hline 2 & $18: 30-20: 30$ & 934 & 21 & 43 & 2 & $32.8(21.6-45.7)$ \\
& $20: 30-22: 30$ & 892 & 33 & 37 & 2 & $47.1(35.1-59.4)$ \\
& $05: 00-07: 00$ & 947 & 41 & 34 & 1 & $54.7(42.8-66.2)$ \\
& Total & 2,773 & 95 & 114 & 5 & $45.5(38.6-52.5)$ \\
\hline
\end{tabular}




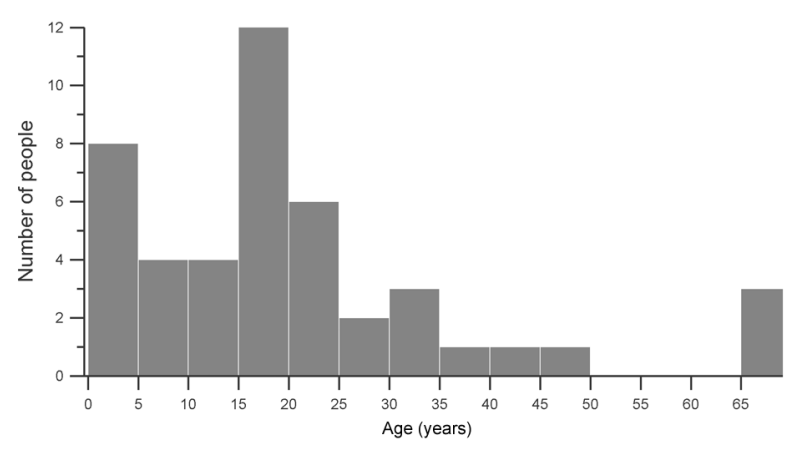

Fig. 4: age distribution of inhabitants in Blondin village.

An. darlingi parity assessed from 05:00 to 07:00 [54.7\%, CI95\% (42.7-66.2)] was significantly higher $(\mathrm{p}=0.01$, Fisher's exact test) than the An. darlingi parity assessed from 18:30 to 20:30 [32.8\%, CI95\% (21.6-45.7)].

Survey interview - Among 60 inhabitants in Blondin village, 46 were questioned - 26 males $(56.5 \%)$ and 20 females $(43.5 \%)$ whose median age was 19 years $(\mathrm{min}=$ six months, $\max =71$ years). The distribution of Blondin village residents by age class (period of five years) is represented in Fig. 4. The majority of the participants $(93.5 \%, \mathrm{n}=43)$ have lived in the village since its creation or from birth. The rest of the participants $(6.5 \%, \mathrm{n}=3)$ arrived in the village the year preceding the study.

In total, 95.7\% $(n=44)$ of the respondents acknowledged using LLINs each night when they went to bed. The mean hour at which participants went to bed was 21:14 [CI95\% (20:53-21:35)] and the mean hour at which they arose was 6:44 [CI95\% (6:26-7:02)]. Only three participants $(6.5 \%)$ used repellents for personal protection against mosquito bites.

Distributions of awake and sleeping people by time slot and the cumulative percentage of people exposed to An. darlingi bites are shown in Fig. 5.

At the time of survey, 52.2\% $(\mathrm{n}=24)$ and $37.0 \%(\mathrm{n}=$ 17) of the participants acknowledged having contracted malaria at least once during 2012-2013 study period. As shown in Fig. 6, the median bedtime hour $(22: 00,25 \%$ percentile of $21: 00$ and $75 \%$ percentile of 23:00) for peo- ple who suffered more than two malaria episodes during 2012 and 2013 was significantly higher than the median (21:00, $25 \%$ percentile at $20: 00$ and $75 \%$ percentile at 22:00) in people who had no or only one malaria episode ( $\mathrm{p}=0.03$, Mann Whitney test).

Among the people who suffered from malaria episodes in $2012(\mathrm{n}=24), 12.5 \%(\mathrm{n}=3)$ were below five years old and $87.5 \%(n=21)$ were above five years old. Participants who had malaria in 2013 represented $37.0 \%$ $(\mathrm{n}=17)$. Of these, $5.9 \%(\mathrm{n}=1)$ were below five years old and $94.1 \%(n=16)$ were above five years old. Fig. 7 shows the variation in malaria episodes for the years 2012 and 2013 according to participants. During 2012, malaria episodes were more numerous from January to March and then from October to December. In 2013, malaria episodes essentially occurred from January to April and in December.

\section{DISCUSSION}

The current study was designed to unravel malaria transmission mechanisms and to determine whether the currently implemented malaria vector control strategies are tailored to the behaviour of the main vectors

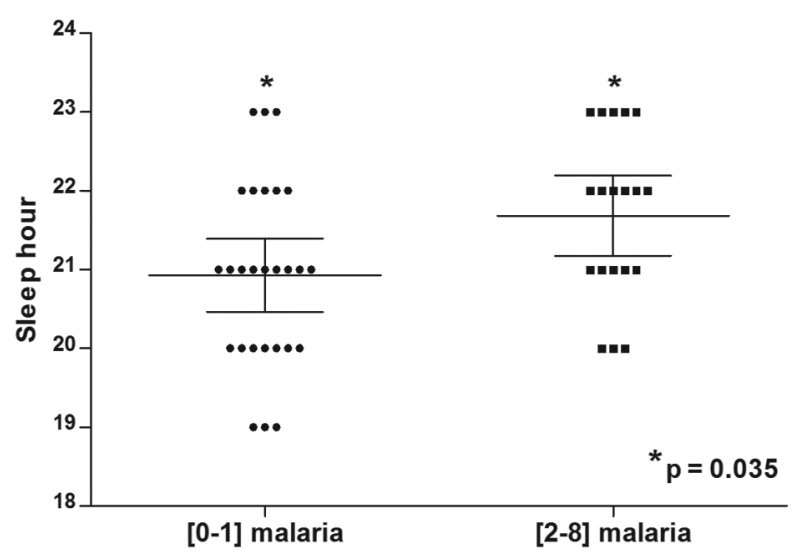

Fig. 6: comparison of hours at which people retire between those who suffered (0-1) and (2-8) malaria episodes during 2012 and 2013, respectively, in Blondin village, Saint-Georges de l'Oyapock municipality, French Guiana.
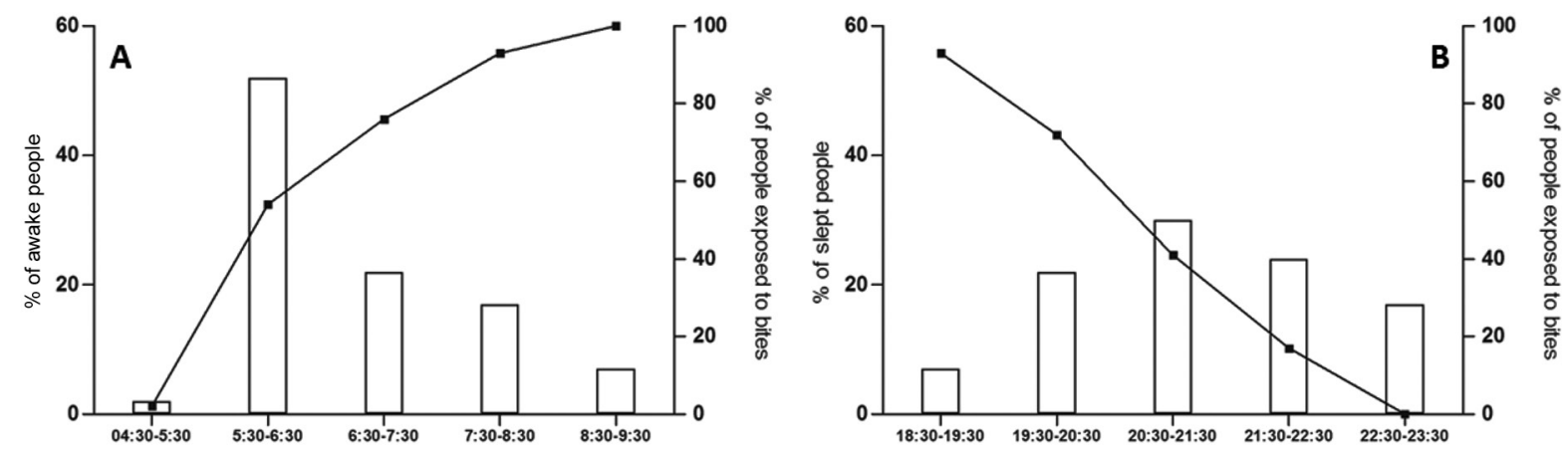

Fig. 5: (A) percentages of people awake (bars) and exposed to Anopheles darlingi bites (curves) by time slot; (B) percentages of people sleeping (bars) and exposed to An. darlingi bites (curves) by time slot. 


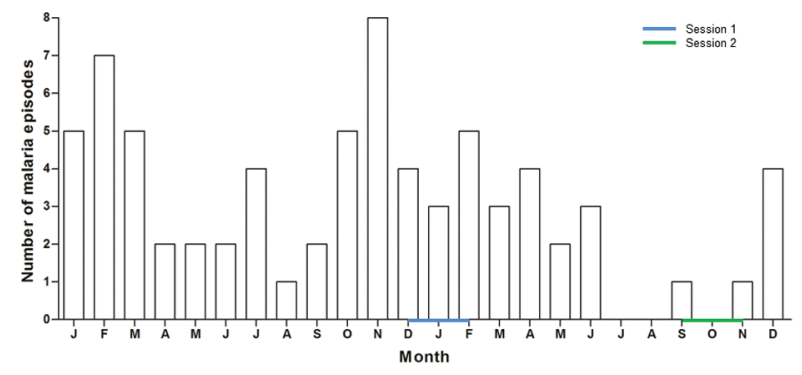

Fig. 7: evolution of malaria episodes by participants during the years 2012 and 2013 in Blondin village, Saint-Georges de l'Oyapock municipality, French Guiana.

and human inhabitants. The study was carried out in Blondin Village, in the municipality of Saint-Georges de l'Oyapock, one of several areas in French Guiana where residual malaria transmission still challenges the control programme instituted by health authorities. The data collected in this study indicate that An. darlingi is predominant of the four anopheline species present. This observation is in accord with the findings of other studies carried out in the territory (Girod et al. 2008, 2011, Hiwat et al. 2009, Fouque et al. 2010, Dusfour et al. 2012). An. darlingi was significantly more abundant during session 2, which corresponded to the long dry season in French Guiana. Similar situations have already been observed in other areas in Amazonia (Gil et al. 2003). However, the peak abundance of this species has been more frequently reported in the rainy season in French Guiana (Magris et al. 2007, Girod et al. 2008, 2011, Hiwat et al. 2009, Fouque et al. 2010) as well as in other areas (da Silva-Vasconcelos et al. 2002, de Barros \& Honorio 2007, Moreno et al. 2007). Because sampling during session 2 started in the middle of the long dry season, the observed abundance can be attributed to the availability of large residual water collections left behind from precipitation during the preceding long rainy season and/or floods as the river progressively retreated to its lowest level. These breeding sites result in mass production of adult mosquitoes at the beginning of the long dry season, generating high densities of adult mosquitoes during the second part of the long dry season. Sampling performed during session 1 coincided with the short rainy season just after the long dry season. The end of the long dry season is characterised by a decrease in flooding of the Oyapock River which, together with the limited rainfall, resulted in few breeding sites and, consequently, the low number of An. darlingi collected.

To investigate the role of anopheline species in malaria transmission in the village, collected mosquitoes were screened for both $P$. vivax and $P$. falciparum infection. An. darlingi collected during session 1 was the only species infected with $P$. vivax. The involvement of An. darlingi in malaria transmission is well documented in South America, especially in French Guiana (Girod et al. 2008, 2011, Hiwat et al. 2009, Fouque et al. 2010). Unexpectedly, no specimens from session 2 were infected with Plasmodium species. One possible explana- tion is that interview responses indicated that malaria cases reached zero prior to mosquito collection during the second session. In contrast, session 1 followed a period during which the number of reported malaria cases was much more significant, which may explain the observed infection rates. In the current study, the global three-month EIR estimating the level of malaria transmission during the high-risk period was calculated during session 1 and based on six hours of mosquito bites exposures per night. This three-month EIR corresponds to 35.7 infective bites/person/three months [CI95\% (25.0-49.4)], which is high compared to annual EIR for other parts of French Guiana such as the Upper-Maroni area with a range of 14.4 to 27.4 infective bites/person/ year (Girod et al. 2008), Apatou with 5.7 infective bites/ person/year, Regina with 8.7 infective bites/person/year (Girod et al. 2011), Loca with 10.0 infective bites/person/year and Twenke with 5.0 infective bites/person/ year (Fouque et al. 2010). Although the time units used to calculate the EIR in these studies differs, the present data clearly suggest that Blondin village is a high-risk area for contracting malaria.

The behaviour of both An. darlingi and humans in Blondin village were studied to gather baseline data to assist in realigning current malaria control strategies. The biting behaviour of $A n$. darlingi reached a peak from 20:30-22:30 in session 1; however, during session 2, there was no statistically significant difference between the percentages of An. darlingi collected during the three time slots. First, this can be attributed to the high number of An. darlingi landing simultaneously on humans' legs, generating a saturation effect during the collections. Second, it has already been reported that the biting behaviour of An. darlingi can differ based on the season (Charlwood 1996, Voorham 2002, Leon et al. 2003, Zimmerman et al. 2013). The evening peak biting time in session 1 corresponded to the village residents' mean bedtime; however, prior to this time, biting activity (which began as soon as 18:30) progressively increased while the majority of the people were still awake and exposed to mosquito bites. Similarly, early in the morning, although the biting rate is low, most of the village inhabitants are out of bed and exposed to An. darlingi bites. Moreover, parity being more important in the morning, inhabitants are exposed to the bites of older females, increasing the likelihood of malaria transmission. Finally, considering the number of malaria cases reported by residents and their sleeping hours, it is clear that people not protected by bednets at the beginning of the night and early in the morning are at high risk of contracting malaria.

Inhabitants exposed to infective mosquito bites during these periods should adopt additional personal protection measures such as cutaneous repellents and mosquito coils and should wear clothing - if possible, impregnated with insecticide - that covers the body. Interestingly, most of the inhabitants did not use any of these personal protective measures.

The structure of houses in this area might also bear some responsibility in malaria transmission. The village's wooden-walled houses had gaps that may allow mosquitoes to move in and out. Coupled with the lack 
of ceilings these structures provide favourable mosquito environments and contribute to the occupants' risk of contracting malaria. In this situation, the use of LLINs and IRS are essential to protect inhabitants - but not sufficient. French Guiana is truly in urgent need of study regarding the effectiveness of IRS and the indoor resting behaviour of An. darlingi. In this work, IRS was carried out in September, before the peak of transmission. Nevertheless the data showed a peak in the number of cases in October. Due to location of the houses relative to potential breeding sites and the evident exophilic and exophagic behaviour of An. darlingi, it would be interesting to develop complementary strategies to protect people. For example, using "pull and push" or "lure and kill" approaches employing attractant-baited traps and repellents or toxic compounds or screens impregnated with insecticides placed between the resting and breeding sites and the houses could constitute a realistic option considering the size and configuration of the village (Burkot et al. 2013, Matowo et al. 2013, Menger et al. 2015).

Malaria vector control strategies should be aligned with the behaviours of both the malaria vectors and the human population to be protected. An. darlingi, the dominant of four Anopheles species identified in an area of residual malaria transmission in French Guiana, has been incriminated as the main vector of $P$. vivax. In the studied village, inhabitants' outdoor activities just after dusk and at dawn favour exposure to An. darlingi infective bites. Consequently, even though LLINs coverage in the village exceeds the Roll Back Malaria target of $80 \%$ and IRS are applied just before the peak transmission period, these control strategies do not provide complete protection. This study recommends the use of individual protective measures and also highlights the need to test innovative collective measures to protect people against outdoor bites from Anopheles.

\section{ACKNOWLEDGEMENTS}

To the inhabitants of Blondin village, for their hospitality.

\section{REFERENCES}

Ardillon V, Carvalho L, Prince C, Abboud P, Djossou F. Bilans 2013 et 2014 de la situation du paludisme en Guyane. BVS. 2015; 1: 16-20.

Birley MH, Charlewood JD. Sporozoite rate and malaria prevalence. Parasitol Today. 1987; 3(8): 231-2.

Burkot TR, Russell TL, Reimer LJ, Bugoro H, Beebe NW, Cooper $\mathrm{RD}$, et al. Barrier screens: a method to sample blood-fed and hostseeking exophilic mosquitoes. Malar J. 2013; 12: 49.

Carme B, Ardillon V, Girod R, Grenier C, Joubert M, Djossou F, et al. Update on the epidemiology of malaria in French Guiana. Med Trop. 2009; 69(1): 19-25.

Charlwood JD. Biological variation in Anopheles darlingi root. Mem Inst Oswaldo Cruz. 1996; 91(4): 391-8.

CIRE AG. Surveillance épidémiologique: du paludisme en Guyane. Institut de Veille Sanitaire. 2006. Available from: http://www.invs.sante. fr/publications/2006/paludisme_guyane/paludisme_guyane.pdf.

da Silva-Vasconcelos A, Kató MYN, Mourão EN, de Souza RTL, Lacerda RNL, Sibajev A, et al. Biting indices, host-seeking activity and natural infection rates of anopheline species in Boa Vista, Roraima, Brazil, from 1996 to 1998. Mem Inst Oswaldo Cruz. 2002; 97(2): 151-61. de Barros FSM, Honorio NA. Man biting rate seasonal variation of malaria vectors in Roraima, Brazil. Mem Inst Oswaldo Cruz. 2007; 102(3): 299-302.

Detinova TS. Age-grouping methods in Diptera of medical importance with special reference to some vectors of malaria. Monogr Ser World Health Organ. 1962; 47: 13-191.

Dusfour I, Carinci R, Gaborit P, Issaly J, Girod R. Evaluation of four methods for collecting malaria vectors in French Guiana. J Econ Entomol. 2010; 103(3): 973-6.

Dusfour I, Carinci R, Issaly J, Gaborit P, Girod R. A survey of adult anophelines in French Guiana: enhanced descriptions of species distribution and biting responses. J Vector Ecol. 2013; 38(2): 203-9.

Dusfour I, Issaly J, Carinci R, Gaborit P, Girod R. Incrimination of Anopheles (Anopheles) intermedius Peryassú, An. (Nyssorhynchus) nuneztovari Gabaldón, An. (Nys.) oswaldoi Peryassú as natural vectors of Plasmodium falciparum in French Guiana. Mem Inst Oswaldo Cruz. 2012; 107(3): 429-32.

Faran ME, Linthicum KJ. A handbook of the Amazonian species of Anopheles (Nyssorhynchus) (Diptera: Culicidae). Mosq Syst. 1981; 13: 1-81.

Floch H, Abonnenc E. Anophèles de la Guyane française. Archs Inst Past Guy. 1951; 236: 1-92.

Floch H. Antimalarial campaign in French Guiana. I. Anophelism. Riv Malariol. 1955; 34(1-3): 57-65.

Forattini OP. Entomologia médica: Parte geral, Diptera, Anophelini. São Paulo: Faculdade de Saúde Pública da Universidade de São Paulo; 1962.

Fouque F, Gaborit P, Carinci R, Issaly J, Girod R. Annual variations in the number of malaria cases related to two different patterns of Anopheles darlingi transmission potential in the Maroni area of French Guiana. Malar J. 2010; 9: 80.

Gil LH, Alves FP, Zieler H, Salcedo JM, Durlacher RR, Cunha RP, et al. Seasonal malaria transmission and variation of anopheline density in two distinct endemic areas in Brazilian Amazonia. J Med Entomol. 2003; 40(5): 636-41.

Girod R, Gaborit P, Carinci R, Issaly J, Fouque F. Anopheles darlingi bionomics and transmission of Plasmodium falciparum, Plasmodium vivax and Plasmodium malariae in Amerindian villages of the Upper-Maroni Amazonian forest, French Guiana. Mem Inst Oswaldo Cruz. 2008; 103(7): 702-10.

Girod R, Roux E, Berger F, Stefani A, Gaborit P, Carinci R, et al. Unravelling the relationships between Anopheles darlingi (Diptera: Culicidae) densities, environmental factors and malaria incidence: understanding the variable patterns of malarial transmission in French Guiana (South America). Ann Trop Med Parasitol. 2011; 105(2): 107-22.

Hay SI, Rogers DJ, Toomer JF, Snow RW. Annual Plasmodium falciparum entomological inoculation rates (EIR) across Africa: literature survey, Internet access and review. Trans R Soc Trop Med Hyg. 2000; 94(2): 113-27.

Hiwat H, Bretas G. Ecology of Anopheles darlingi root with respect to vector importance: a review. Parasite Vectors. 2011; 4: 177.

Hiwat H, de Rijk M, Andriessen R, Koenraadt CJ, Takken W. Evaluation of methods for sampling the malaria vector Anopheles darlingi (Diptera, Culicidae) in Suriname and the relation with its biting behavior. J Med Entomol. 2011; 48(5): 1039-46.

Hiwat H, Issaly J, Gaborit P, Somai A, Samjhawan A, Sardjoe P, et al. Behavioral heterogeneity of Anopheles darlingi (Diptera: Culicidae) and malaria transmission dynamics along the Maroni River, Suriname, French Guiana. Trans R Soc Trop Med Hyg. 2009; 104(3): 207-13. 
Laporta GZ, Linton YM, Wilkerson RC, Bergo ES, Nagaki SS, Sant'Ana DC, et al. Malaria vectors in South America: current and future scenarios. Parasite Vectors. 2015; 8: 426.

Leon C, Valle J, Naupay R, Tineo E, Rosas A, Palomino R. Comportamiento estacional del Anopheles (Nyssorhynchus) darlingi root 1926 en localides de Loreto y Madre de Dios, Peru, 1999-2000. Rev Peru Med Exp Salud Publica. 2003; 36: 75-80.

Magris M, Rubio-Palis Y, Menares C, Villegas L. Vector bionomics and malaria transmission in the Upper Orinoco River, Southern Venezuela. Mem Inst Oswaldo Cruz. 2007; 102(3): 303-11.

Mansotte F, Ravachol F, Carlisi R, Caudal J, Pinchon S, Maison D. Operation to promote use of long-lasting insecticidal nets (LLIN) in French Guiana in 2006: design, implementation and results. Med Trop. 2010; 70(3): 249-54.

Matowo NS, Moore J, Mapua S, Madumla EP, Moshi IR, Kaindoa EW, et al. Using a new odour-baited device to explore options for luring and killing outdoor-biting malaria vectors: a report on design and field evaluation of the Mosquito Landing Box. Parasite Vectors. 2013; 6: 137.

Menger DJ, Omusula P, Holdinga M, Homan T, Carreira AS, Vandendaele $\mathrm{P}$, et al. Field evaluation of a push-pull system to reduce malaria transmission. PLoS ONE. 2015; 10(4): e0123415.

Moreno JE, Rubio-Palis Y, Paez E, Perez E, Sanchez V. Abundance, biting behaviour and parous rate of anopheline mosquito species in relation to malaria incidence in gold-mining areas of southern Venezuela. Med Vet Entomol. 2007; 21(4): 339-49.

Moreno M, Saavedra MP, Bickersmith SA, Lainhart W, Tong C, Alava F, et al. Implications for changes in Anopheles darlingi biting behaviour in three communities in the peri-Iquitos region of Amazonian Peru. Malar J. 2015; 14: 290.

Musset L, Pelleau S, Girod R, Ardillon V, Carvalho L, Dusfour I et al. Malaria on the Guiana Shield: a review of the situation in French Guiana. Mem Inst Oswaldo Cruz. 2014; 109(5): 525-533.

Pajot FX, Le Pont F, Molez JF, Degallier N. Agressivité d'Anopheles (Nyssorhynchus) darlingi Root 1926 (Diptera: Culicidae) en Guyane Française. Cah ORSTOM, Sér Entomol Méd Parasitol. 1977; 15: 15-22.

Pommier de Santi V, Dia A, Adde A, Hyvert G, Galant J, Mazevet M, et al. Malaria in French Guiana linked to illegal gold mining. Emerg Infect Dis. 2016a; 22(2): 344-6.

Pommier de Santi V, Djossou F, Barthes N, Bogreau H, Hyvert G, Nguyen C, et al. Malaria hyperendemicity and risk for artemisinin resistance among illegal gold miners, French Guiana. Emerg Infect Dis. 2016b; 22(5): 903-6.

Pommier de Santi V, Girod R, Mura M, Dia A, Briolant S, Djossou F, et al. Epidemiological and entomological studies of a malaria outbreak among French armed forces deployed at illegal gold mining sites reveal new aspects of the disease's transmission in French Guiana. Malar J. 2016c; 15: 35.

Roberts DR, Manguin S, Rejmankova E, Andre R, Harbach RE, Vanzie E, et al. Spatial distribution of adult Anopheles darlingi and Anopheles albimanus in relation to riparian habitats in Belize, Central America. J Vector Ecol. 2002; 27(1): 21-30.

Rozendaal JA. Biting and resting behavior of Anopheles darlingi in the Suriname rainforest. J Am Mosq Control Assoc. 1989; 5(3): 351-8.

Sinka ME, Rubio-Palis Y, Manguin S, Patil AP, Temperley WH, Gething PW, et al. The dominant Anopheles vectors of human malaria in the Americas: occurrence data, distribution maps and bionomic precis. Parasite Vectors. 2010; 3: 72.

Smith DL, Guerra CA, Snow RW, Hay SI. Standardizing estimates of the Plasmodium falciparum parasite rate. Malar J. 2007; 6: 131.

Smith DL, McKenzie FE. Statics and dynamics of malaria infection in Anopheles mosquitoes. Malar J. 2004; 3: 13.

Smith DL, Smith TA, Hay SI. Measuring malaria for elimination. In: Feachem RGA, Phillips AA, Targett GA, editors. Shrinking the malaria map. A prospectus on malaria elimination. San Francisco: The Global Health Group; 2009. p. 108-26.

Snounou G, Viriyakosol S, Zhu XP, Jarra W, Pinheiro L, do Rosario VE, et al. High sensitivity of detection of human malaria parasites by the use of nested polymerase chain reaction. Mol Biochem Parasitol. 1993; 61(2): 315-20.

Talaga S, Dejean A, Carinci R, Gaborit P, Dusfour I, Girod R. Updated checklist of the mosquitoes (Diptera: Culicidae) of French Guiana. J Med Entomol. 2015; 52(5): 770-82.

Vezenegho SB, Adde A, Gaborit P, Carinci R, Issaly J, Pommier de Santi V, et al. Mosquito magnet(R) liberty plus trap baited with octenol confirmed best candidate for Anopheles surveillance and proved promising in predicting risk of malaria transmission in French Guiana. Malar J. 2014; 13: 384.

Vezenegho SB, Carinci R, Gaborit P, Issaly J, Dusfour I, Briolant S, et al. Anopheles darlingi (Diptera: Culicidae) dynamics in relation to meteorological data in a cattle farm located in the coastal region of French Guiana: advantage of mosquito magnet trap. Environ Entomol. 2015; 44(3): 454-62.

Voorham J. Intra-population plasticity of Anopheles darlingi's (Diptera, Culicidae) biting activity patterns in the state of Amapá, Brazil. Rev Saude Publica. 2002; 36(1): 75-80.

WHO - World Health Organization. Manual on practical entomology in malaria. Part II. Methods and techniques. Geneva: Division of Malaria and Other Parasitic Diseases; 1975.

Zimmerman RH, Lounibos LP, Nishimura N, Galardo AK, Galardo $\mathrm{CD}$, Arruda ME. Nightly biting cycles of malaria vectors in a heterogeneous transmission area of eastern Amazonian Brazil. Malar J. 2013; 12: 262. 